\title{
Effect of Emergency Department Crowding on the Outcome of Cardiac Arrest in South Korea.
}

\section{Seung-Joon Lee, MD*, Jin-Hee Lee, PhD}

National Emergency Medical Center, National Medical Center, Seoul, South Korea

\section{BACKGROUND:}

Successful resuscitation following cardiac arrest requires substantial resources and commitment during cardiopulmonary resuscitation (CPR). Emergency department (ED) overcrowding may interfere with the provision of optimal care, and thus may affect the outcome of cardiac arrest. We evaluated the effect of ED crowding on the outcome of cardiac arrest patients who received CPR in ED.

\section{METHODS:}

The National Emergency Department Information System (NEDIS), a nationwide observational registry for ED information in South Korea was used in this study. Patients with cardiac arrest received CPR in ED during 2017 were included. The definition of crowdedness in ED was 80th percentile of number of patients staying in hourly distribution of all visits which calculated in each ED. Odds ratio of survival discharge rate according to ED crowding was analyzed by logistic regression analysis.

\section{RESULTS:}

During the study period, 27,724 patients with cardiac arrest in 404 hospitals were included in this study. 7,526 patients visited while ED is crowding and were assigned by crowding group, and 20,198 were non-crowding group. Crowding group showed a higher rate of survival discharge from ED than non-crowding group (odds ratio [OR], 1.06; 95\% confidence interval [Cl],

1.00-1.13).

Subgroup analyses showed similar results across the subgroups; at day-time (9am-6pm) (OR, 1.01; 95\% Cl, 0.93-1.10), at night-time (OR, 1.11; 95\% Cl, 1.01-1.21), in highvolume hospitals (OR, $1.07 ; 95 \% \mathrm{Cl}$, 0.98-1.17), in lowvolume hospitals (OR, 1.06; $95 \% \mathrm{Cl}$, 0.97-1.15).

\section{CONCLUSION:}

ED crowding did not decrease the survival discharge rate of cardiac arrest patients who received CPR in ED in South Korea.

The authors have no conflict of interest to disclose.
Table 1. Comparison of the survival discharge rate from ED between crowding group and non-crowding group.

\begin{tabular}{|c|c|c|c|c|c|}
\hline & \multirow[b]{2}{*}{$\mathrm{N}$} & \multicolumn{2}{|c|}{ Survival discharge from ED } & \multirow[b]{2}{*}{ OR (95\% Cl) } & \multirow[b]{2}{*}{ P Value } \\
\hline & & $\begin{array}{l}\text { Crowding } \\
\text { group(\%) }\end{array}$ & $\begin{array}{l}\text { Non-Crowding } \\
\text { group(\%) }\end{array}$ & & \\
\hline Total & 27,724 & 28.30 & 27.07 & $1.06(1.00-1.13)$ & 0.04 \\
\hline \multicolumn{6}{|l|}{ Visit time } \\
\hline Day & 13,234 & 28.38 & 28.10 & $1.01(0.93-1.10)$ & 0.74 \\
\hline Night & 14,490 & 28.21 & 26.22 & $1.10(1.01-1.21)$ & 0.02 \\
\hline \multicolumn{6}{|l|}{ Hospital volume } \\
\hline High-volume & 13,858 & 28.08 & 26.72 & $1.07(0.98-1.17)$ & 0.11 \\
\hline Low-volume & 13,866 & 28.50 & 27.43 & $1.06(0.97-1.15)$ & 0.20 \\
\hline \multicolumn{6}{|l|}{ Age group, year } \\
\hline$<16$ & 523 & 36.11 & 31.13 & $1.25(0.84-1.87)$ & $0.2 \varepsilon$ \\
\hline $16-60$ & 9,225 & 34.41 & 33.09 & $1.06(0.96-1.17)$ & 0.23 \\
\hline$>60$ & 17,976 & 24.97 & 23.85 & $1.06(0.99-1.15)$ & 0.12 \\
\hline
\end{tabular}

